\title{
La influencia de la ecología, la cultura y el contacto con la civilización europea en el desarrollo cognitivo de los aborígenes australianos ${ }^{* *}$
}

\section{P. R. Dasen}

\author{
Traducción de Elena Martín y Amparo Moreno
}

La teoría de Piaget se ha estudiado extensamente en culturas no-occidentales durante los diez últimos años; estos datos son muy ricos pero heterogéneos y están resumidos en otra parte (Dasen, 1972 a). Siempre que se aplican las pruebas piagetianas en culturas no-occidentales se encuentran los estadios definidos originalmente por Piaget, pero el ritmo de desarrollo se ve afectado normalmente por las influencias ambientales. La tendencia actual de la investigación transcultural en esta área consiste en ir más allá de una simple réplica de la teoría de Piaget, utilizando las diferencias culturales específicas en una situación cuasi experimental para establecer con mayor precisión las influencias ambientales.
Este artículo describe un estudio sobre el desarrollo cognitivo de dos grupos de aborígenes australianos que diferían en su grado de contacto con la civilización europea, e intenta relacionar el ritmo de desarrollo en distintas áreas del desarrollo cognitivo con las características ecológicas y culturales.

Hay dos estudios anteriores que están directamente relacionados con este proyecto. De Lemos $(1966,1969$ b), estudió el desarrollo de los conceptos de conservación de la cantidad, peso, volumen, longitud, área y número en dos grupos de niños aborígenes australianos que vivían en misiones remotas. De Lemos encontró que aquellos niños que realmente adquirían los conceptos de conservación lo hacían, desde el punto de vista cuali-

* Esta investigación estaba financiada por una beca de investigación de la Universidad Nacional australiana (Canberra, A.C.T.); la preparación de este informe ba sido posible gracias a una beca de Fonds National Suisse de la Recherche Scientifique a la profesora Bärbel Inbelder (Beca núm. I. 133-69). Agradezco al profesor G. N. Seagrim la orientación que me ba prestado, a Catberine Dasen su ayuda en la recogida y análisis de los datos, y a La Misión de Finke River, al Departamento de Asistencia Social de la Administración de los territorios del Norte y al Departamento de Educación de Nuevo Gales del Sur por facilitarme la entrada en las escuelas.

** Fuente: BERRY, J. W. y DASEN, P. R. (eds.) (1974), Culture and cognition: readings in cross-cultural psychology, Londres, Methuen, pp. 381-408. 
tativo, exactamente de la misma forma descrita por Piaget, es decir pasando por los mismos subestadios en estas pruebas, y dando las mismas explicaciones de sus respuestas que los niños europeos. El ritmo de desarrollo, sin embargo, era más lento que en los niños europeos y las curvas de desarrollo eran asintóticas (i. e. algunos niños no adquirían en absoluto los conceptos).

De Lacey (1970 a, b) aplicó cuatro pruebas piagetianas de clasificación a cuatro muestras de niños australianos. Dos de ellas eran muestras de niños aborígenes australianos; uno de los grupos vivía en comunidades principalmente aborígenes, rurales y aisladas, y el otro vivía en un contacto con Ios europeos mucho mayor. Las dos muestras de niños europeos se identificaron con niveles socioeconómicos alto y bajo. El ritmo de desarrollo de los conceptos clasificatorios era extremadamente bajo en el grupo de poco contacto, dando lugar a curvas similares a las encontradas por De Lemos. En cambio, una submuestra de aborígenes con mucho contacto con europeos tuvieron una ejecución igual o mejor que los niños australianos blancos de nivel socioeconómico bajo.

\section{LA VARIABLE CONTACTO CON LA CIVILIZACION EUROPEA}

En el estudio de De Lacey, la diferencia en contacto con la civilización europea entre las dos muestras aborígenes era máxima. Los dos grupos vivían en áreas muy diferentes de Australia, manteniendo el grupo de poco contacto la mayoría de sus tradiciones y la lengua, mientras que el grupo de mucho contacto había perdido totalmente su cultura, se había despojado de todos los aspectos de los valores y la cultura aborígenes, hablaba solamente inglés, acudía a las mismas escuelas que sus pares europeos, y vivía en gran parte la vida de los europeos pobres.

En este estudio los dos grupos de niños aborígenes se diferencian también en cuanto a la variable contacto europeo, pero son más semejantes en otros muchos aspectos: ambos grupos viven en una región semi-desértica al oeste de Alice Springs, en el centro de Australia, en comunidades aisladas principalmente aborígenes; los dos grupos han mantenido algunos o la mayoría de sus valores y costumbres aborígenes, hablan su lengua vernácula, utilizando el inglés sólo en las escuelas; los dos grupos viven a cargo de la asistencia social o, incluso si están contratados, no establecen relaciones directas con la economía europea.

El grupo de poco contacto está formado por aborígenes Pitjantjara (Pitjantjajara) que viven en la Colonia Gubernamental de Areyonga, que se estableció como reserva en 1944 y que ha contado con una escuela desde 1950 y un dispensario médico desde 1952. Ha habido contacto entre las tribus del Desierto Occidental y los misioneros europeos desde 1920, pero, incluso cuando se estableció Areyonga, el contacto con la cultura europea era sólo esporádico, se limitaba principalmente a la distribución de mercancías, y la población ha seguido siendo nómada en su mayoría. En los años siguientes algunos aborígenes se hicieron más sedentarios, pero las tradiciones y costumbres revivían constantemente con la llegada de nuevos grupos desde el desierto (hasta 1965 aproximadamente). En 1969, cuando se realizó este estudio, la población aborigen de Areyonga se había hecho sedentaria durante una parte del año, aunque la mayor parte de las familias no utilizaban las casas que la colonia ofrecía, sino que vivían en chozas metálicas que se parecían a. los refugios tradicionales y que podian moverse de vez en cuando. Sin embargo, durante cuatro meses aproximadamente cada año, la mayor parte de la población sigue abandonando este lugar para «ir y venir» visitando sus ancestrales lugares sagrados y realizando ceremonias, viajando a través de grandes distancias por el Desierto Occidental, y viviendo de la caza y la recolección principalmente. Durante los meses sedentarios, los niños acuden a la escuela de forma más o menos regular y la mayor parte de los adultos tiene algún tipo de empleo, aunque estos trabajos tienden a ser bastante artificiales ya que no existe un motivo económico real para ellos, excepto el bienestar social. El acceso a la colonia, que está situada en la Reserva 1028, está restringido y se necesita un permiso expedido por la administración de asisțencia social; el acceso se ve dificultado además por la distancia $(224 \mathrm{Km}$. aproximadamente desde Alice Springs) y las malas condiciones de las carreteras.

El grupo con contacto medio con la civilización europea está formado por aborígenes Aranda (Arunta) que viven en la Misión Hermannsburg, que fue fundada en 1877, con actividades escolares que se remontan a 1880 . La enseñanza escolar se impartía al principio en Aranda, pero desde 1930 el inglés fue ganando importancia hasta convertirse finalmente en la única lengua en la enseñanza; 
el curriculum y los recursos educativos tenían un nivel muy básico hasta los años 50. En 1969, las condiciones escolares en Areyonga y Hermannsburg eran bastante similares, aunque Hermannsburg tenia un equipo ligeramente mejor y el personal era más estable. La población aborigen de Hermannsburg sigue utilizando casi únicamente la lengua vernácula, pero han abandonado hasta cier. to punto los valores y tradiciones aborigenes, sin haberlos sustituido necesariamente por los equivalentes europeos. Las casas suelen ser mejores las de Areyonga, aunque esto es un logro reciente y algunas familias son trasladadas a chozas metálicas. La población es más estable que en Areyonga; no existe el «ir y venir" anual, aunque muchos, aborígenes suelen viajar frecuentemente a otras colonias. Los adultos tienien empleos semejantes a los de Areyonga, pero la misión cuenta también con una industria productiva de ganado y una curtiduría, y la economía de dinero en efectivo se ve favorecida por un almacén bien equipado. El acceso a Hermannsburg es libre, y los autobuses de turistas visitan regularmente la misión; el lugar está unido al centro europeo más cercano por $112 \mathrm{Km}$. de una carretera que se encuentra en un estado relativamente bueno.

Al aplicar el «índice de contacto» de De Lacey (De Lacey, 1970 c) a las dos muestras, Areyonga da un indice de 0,13 y Hermannsburg de 0,39 (máximo 1,00 ). Esto puede compararse con el 0,13 para el grupo de poco contacto de De Lacey, y el 0,83 para su grupo de mucho contacto (De Lacey, 1970 b).

La mayoría de los estudios anteriores sobre psicología piagetiana transcultural que se han ocupado de la variable contacto con la civilización europea han intentado extremar las diferencias entre las muestras que se iban a comparar; además, han utilizado la diferencia urbano/rural (Greenfield, 1966; Peluffo, 1967; Poole, 1968; Vernon, 1969; De Lacey, $1980 \mathrm{~b}$ ), o bien la diferencia instruido/analfabeto (Greenfield, 1966 Hendrikz, 1966) o ambas (Mohseni, 1966). En este estudio, en cambio, los niños de las dos muestras viven en comunidades rurales y reciben el mismo tipo de escolarización; la diferencia principal reside en la duración del contacto europeo y en el grado en que se han mantenido los valores $y$ actividades tradicionales. Se hipotetiza que, a pesar de la diferencia relativamente escasa que existe entre los dos grupos, se encontrará una diferencia significativa en el ritmo de desarrollo cognitivo.

\section{LA VARIABLE ECOLOGICA/ CULTURAL}

Berry (1966 b, 1971) ha defendido que las exigencias ecológicas identificadas en un grupo de personas, más su adaptación cultural a esta ecología («ayudas culturales") llevarán al desarrollo de unas ciertas habilidades espaciales y perceptuales. "El desarrollo cultural y el psicológico son congruentes; las características culturales permiten a las personas desarrollar y mantener aquellas habilidades que necesitan» (Berry, 1966 b, p. 228). Concretamente "se supone que los cazadores poseen una buena discriminación visual y habilidad espacial, y se supone que sus culturas apoyan el desarrollo de estas habilidades por medio de la presencia de un gran número de conceptos "geométricos espaciales", una producción muy desarrollada y normalmente compartida de artes y oficios, prácticas de socialización cuyo contenido hace hincapié en la independencia y confianza en uno mismo, y cuyas técnicas apoyan y fomentan el desarrollo independiente” (Berry, 1971, p. 133).

Berry (1966 b) pudo demostrar que, en cuatro pruebas concebidas como medida de la capacidad espacial (Cubos de Kohs, Test de las figuras encajadas de Witkin, Formas de Morrisby y Matrices de Raven), la ejecución de los esquimales (economía de caza; lenguaje rico en términos espaciales; artes y oficios muy desarrollados; prácticas de socialización indulgentes) no sólo superaba a la de los temne (economía agrícola; lenguaje pobre en términos espaciales; habilidades de artes $y$ oficios pobremente desarrolladas; prácticas de socialización severas) sino que igualaba prácticamente a la de los escoceses (el grupo europeo de referencia).

Más tarde (Berry, 1971) se incluyeron otras muestras que eran ecológicamente intermedias (una de las cuales era una muestra Arunta), y la pauta de los datos mostraba tan sólo un error en la posición ordenada de las variables dependientes.

Ampliando el funcionalismo ecológico de Berry al marco piagetiano, podríamos esperar que las personas con una economía de caza desarrollaran los conceptos de espacio (Piaget e Inhelder, 1956) más que conceptos de otras áreas cognitivas en las que hubiera pocas o ninguna exigencia ecológica.

Los aborígenes australianos dependen tradicionalmente de la caza y la recolección de alimentos, viajando largas distancias en un ambiente relativamente estéril (Hellbush, 1941; Elkin, 1964; 
Strehlow, 1965; y muchos otros). El agua es una comodidad poco común, y los viajes se organizan normalmente para ir desde un charco al siguiente; el aborigen conoce la localización de estos charcos, y por supuesto la de cada uno de los otros rasgos del entorno dentro de una extensa área, de la que parece poseer un detallado "mapa cognitivo», qué le permite encontrar su camino y mostrar direcciones a otros. Los aborígenes no utilizan mapas transportables, pero dibujan mapas simbólicos en el suelo o pintan en las piedras. Estos mapas representan, de una forma sencilla, las posiciones por medio de círculos, conectados por líneas que representan el viaje entre ellas, y que parecen ser precisas en cuanto a la dirección pero no a la distancia. (Analizados en términos piagetianos, estos mapas contienen relaciones espaciales topológicas y proyectivas, pero no euclidianas.)

También se encuentran "ayudas culturales» relacionadas: las tradiciones artísticas aborígenes son bien conocidas (pinturas en cortezas, y más recientemente el estilo Namatjira de color de agua desarrollado en la misión de Hermannsburg) y las prácticas de crianza de los nińos se describen normalmente como muy permisivas (Kaberry, 1939; Malinowski, 1963; Nurcombe y Cawte, 1967; Dawson, 1969).

En cambio, los conceptos de número y medida parecen estar ausentes en la cultura aborigen.

Los aborígenes conocen la recolección de sus alimentos y los lugares donde hay agua y tienen una cierta idea sobre las fronteras de los clanes y tribus... Pero no miden y no poseen términos para expresar tamaño o distancia... Por supuesto, el artesano sabe la longitud que quiere darle a su lanza, pero no en pies o pulgadas. Trabaja con la vista, el peso y la balanza.

Este tema de la medida está relacionado con el problema de los números - un problema real para los aborigenes. Sus lenguas tienen palabras para uno y dos, e indican tres y cuatro diciendo dos-uno y dos-dos respectivamente. A veces indican el cinco con la mano abierta... Pero esto no es contar; se trata sólo de un método concreto para indicar personas y lugares individuales. Después de cinco normalmente dicen muchos, o un "montón" o un "gran montón". Y esto se puede entender bastante bien. Las personas concretas se conocen por sus nombres y sus huellas. Un cazador sólo caza o alancea un canguro cada vez... Asimismo tiene suerte si hiere a más de un ualabi... En consecuencia, aunque los niños en la escuela aprenden a contar de memoria hasta un número dado $\mathrm{y}$ a recitar varias tablas, estos números no tienen ninguna relevancia para la vida de sus padres y sus abuelos -i. e. para la caza y la recolección de alimentos (Elkin, 1964, pp. 236-7).

Strehlow (1944) ha propuesto la misma explicación para la ausencia de un sistema numérico, y aunque muy bien se la puede considerar insatisfactoria (uno desearía seguramente tener más datos antropológicos en relación con el uso de los conceptos básicos), el hecho de que los aborigenes no se interesan por el números son más relevantes ecológica y culturalmente que los últimos.

Podríamos esperar por tanto que los aborígenes australianos desarrollaran conceptos espaciales más fácilmente que conceptos relacionados con el número o la medida (lo que llamaremos conceptos «lógico-matemáticos») ya que los primeros más relevantes ecológica y culturalmente que los últimos.

En los niños europeos esto no es así; podemos ver que las dos áreas del desarrollo conceptual evolucionan conjuntamente durante el período de las operaciones concretas, $o$ incluso pueden adquirirse relativamente antes los conconceptos lógico-matemáticos que los espaciales:

A la edad de siete años como media el niño es capaz de realizar operaciones lógico-aritméticas (clasificaciones, ordenaciones en series y correspondencias término a término) pero es un año más tarde cuando se aprenden las operaciones espacio-temporales (incluyendo las coordenadas, los conceptos proyectivos y la simultaneidad). (Inhelder, 1956, p. 83.)

En términos más generales, nuestra hipótesis es que el ritmo de desarrollo cognitivo puede variar de un área del desarrollo conceptual a otra, por la influencia de las exigencias ecológicas y culturales.

\section{RESUMEN DE LAS HIPOTESIS}

1. Basándonos en los resultados de la mayoría de los estudios anteriores que han tratado el desarrollo de las operaciones concretas en culturas no occidentales (cf. Dasen, 1972 a) y en concreto en el estudio anterior sobre conceptos de conservación en aborígenes australia- 
nos (De Lemos, 1966, 1969 b), proponemos las siguientes hipótesis generales:

Hipótesis 1: Los aspectos cualitativos del desarrollo operacional (i. e. los estadios) son idénticos en los aborígenes australianos y en los europeos, pero el ritmo de desarrollo es más lento en los aborígenes.

2. Basándonos en los anteriores resultados sobre que el contacto europeo, definido en términos generales, favorece el desarrollo de las operaciones concretas en las culturas no occidentales (Greenfield, 1966; Mohseni, 1966; Poole, 1968; Lloyd, 1971 a, b) y en concreto basándonos en el estudio anterior sobre la influencia del contacto europeo en los aborígenes australianos (De Lacey, 1970 b), vamos a poner a prueba la siguiente hipótesis:

Hipótesis 2: El ritmo de desarrollo operacional es más rápido en el grupo de contacto medio (Hermannsburg) que en el grupo de poco contacto (Areyonga).

3. Siguiendo el funcionalismo ecoló gico y cultural de Berry (Berry, $1966 \mathrm{~b}$, 1971), un análisis de la ecología y la cultura de los aborígenes australianos da lugar a la siguiente hipótesis:

Hipótesis 3: Los aborigenes, debido a sus antecedentes ecológicos y culturales, desarrollarán los conceptos es. paciales antes que los conceptos «ló gico-matemáticos».

\section{METODO}

\section{Las muestras}

Se pasaron las pruebas a ciento cuarenta y cinco niños aborígenes australianos, con edades desde 6 a 16 años, y a veinte adultos, en dos localidades diferentes del centro de Australia, ambas al oeste de Alice Springs. El grupo de poco contacto estaba formado por la población escolar completa de la Colonia de Areyonga $(\mathrm{N}=55)$; el grupo de contacto medio $(\mathrm{N}=90)$ era una muestra de los 148 niños que asistian a la escuela de la Misión de Hermannsburg, de tal forma que en cada nivel estaban incluidos cinco niños de cada sexo. En ambos grupos se excluyó de las muestras a los niños cuyas edades no podían establecerse con seguridad, que tenían deficiencias claras en la visión o la audición, o que los maestros reconocian como retrasados mentales. Los adultos, diez en cada muestra, se prestaron voluntariamente porque estaban interesados y/o por los incentivos adicionales de cigarrillos, naranjas o bebidas frías. La edad media de las muestras de adultos era 23,3 años en Areyonga y 25,0 en Hermannsburg; tendían a representar la porción más joven, mejor educada y más culta de la población adulta.

Además se seleccionó un grupo de referencia de ochenta europeos (austraiianos blancos, excluyendo a los niños con origen emigrante, que no tenían un in glés totalmente fluido) de una escuela primaria estatal de un barrio de clase media-baja de Canberra, capital del territorio australiano.

Los grupos de edad se definían como $(n-\mathrm{I}) ; 7$ a $(n) ; 6$ años, p. ej. para 12 años de edad, desde 11 años 7 meses a 12 a 6 meses.

En otra parte (Dasen, 1970) se ofrecen detalles de los procedimientos de muestreo y las características de la muestra.

\section{Condiciones de la prueba}

Se entrevistaba a los niños individualmente, durante las horas normales de colegio. En Hermannsburg y Areyonga dos experimentadores distintos entrevistaban a dos niños a la vez en la misma habitación, pero colocados cara a cara lejos el uno del otro. Esto ayudaba a vencer la timidez inicial.

El tiempo total de la prueba variaba de un sujeto a otro, y solía ser (incluyendo las cinco pruebas perceptuales que no se discuten en este artículo) de una a tres horas, con una media de dos horas aproximadamente para los sujetos aborígenes y setenta y cinco minutos para los europeos. Este tiempo total se subdividía en varias sesiones (de dos a seis) de distinta duración (de quince a cuarenta y cinco minutos) dependiendo de la atención del sujeto y el horario escolar. Las sesiones estaban separadas normalmente por uno o dos días.

En Areyonga y Hermannsburg había que emplear una gran cantidad de tiempo en establecer un buen rapport con el niño. Esto se conseguía de la siguiente forma:

1) Primero, los experimentadores asistían a las actividades escolares, mostraban diapositivas y dejaban claro que estaban interesados en lo que los niños hacían y pensaban; también pasaban mucho tiempo con los niños fuera de las horas escolares.

2) En un segundo estadio, los sujetos 
iban a la habitación experimental y se les permitía que jugaran, que miraran álbumes de fotografías que trataban de niños aborígenes, que dibuiaran, y, si era posible, se les pasaba la primera prueba.

En la mayoría de los casos no era necesario dar ningún refuerzo; el «realizar algunos juegos" se consideraba una recompensa por sí mismo. A los sujetos se les animaba con palabras tales como «bien» independientemente de su ejecución real, y no se daba ninguna información posterior de feedback, excepto a algunos sujetos mayores $y$ adultos una vez que se había completado la prueba.

\section{Procedimiento}

Las pruebas estaban basadas en las descritas por Piaget y sus colaboradores, y estandarizadas por Vinh-Bang (en preparación). El procedimiento estaba estandarizado en tanto que se le planteaban los mismos problemas básicos a cada niño, pero se mantenía la flexibilidad del método clínico de Piaget en tanto que a cada niño en concreto se le hacían más preguntas de acuerdo con su respuesta particular. No se utilizaron sugerencias ni contra-sugerencias, que normalmente se hacen para comprobar la estabilidad de las respuestas (1), por la siguiente razón: el niño aborigen no está acostumbrado a expresar y mantener su propia opinión. Es probable que cualquier contrasugerencia se tome como una crítica, y que el sujeto cambie la respuesta. Es difícil decir si el niño cambia o no realmente de opinión: podría dar perfectamente una respuesta que él sabe que está mal, pero que cree que le gustará a la figura autoritaria europea.

Todas las acciones las realizaba el sujeto y no el experimentador; esto se pensó para evitar el que apareciera lo que Greenfield (1966, pp. 245-63) ha llamado "acción mágica», i. e. la atribución de poderes mágicos a una figura de autoridad como el experimentador. Por ejemplo, en la prueba de conservación la falta de conservación puede racionalizarse como habiéndose producido por un poder mágico adulto además de por la transformación física.

Nunca se ponía tiempo límite ni se llevaba a los sujetos a que creyeran que tenían que trabajar o contestar rápidamente. Los procedimientos de la prueba se diseñaron para que resultaran adecuados al grupo de poco contacto; por tanto se utilizaron los mismos procedimientos para. las otras dos muestras, excepto para la muestra europea en la que se utilizó un inglés más sofisticado. Se seleccionaron las pruebas y se adoptaron los procedimientos para preguntar tras un estudio piloto que llevó a cabo en la Colonia Amoonguna, cerca de Alice Springs. Se realizaron algunos cambios en los materiales y los procedimientos a partir de esta prueba. Se encontró, en concreto, que los materiales utilizados por De Lemos (1966) para la conservación de la cantidad (azúcar) y del peso (té en bolsas de plástico de distintos tamaños) no resultaban prácticos, ni parecían ser más familiares para los niños que el agua ( $o$ una bebida estimulante como cordial) y la plastilina; se mantuvieron por tanto los materiales típicos de la prueba. Para la prueba de la seriación se vio que era necesario mostrar un modelo con las instrucciones para la primera parte. Cada prueba iba precedida por un período de entrenamiento $y$ por unos ítems de ensayo para asegurar una comunicación adecuada. Se observaba el vocabulario del niño, y posteriormente se utilizaban las mismas palabras en los items crítiços.

La entrevista se realizaba en inglés. Hubiera resultado imposible aprender las lenguas Pitjantjara y Aranda con un grado de fluidez suficiente en el tiempo de que se disponía para este estudio. Sin embargo, los experimentadores estaban familiarizados con algunas palabras claves de las lenguas vernáculas, y las utilizaban para establecer el contacto o para provocar una respuesta. El Dr. De Lemos realizaba amablemente las traducciones al Aranda, y las traducciones al Pitjantjara eran revisadas a la vez por varios informadores aborígenes y europeos. Como el inglés era la única lengua en la enseñanza, la mayoría de los sujetos entendían preguntas e instrucciones sencillas $y$ sabían hablar lo suficiente para las tareas. Se tenía la sensación de que la comunicación fue siempre la adecuada; los pocos casos en los que no ocurría esto se clasificaron aparte. Se vio que eran imposible utilizar un intérprete porque los europeos que hablan las lenguas aborígenes son escasísimos, y no habrian podido dedicar el tiempo suficiente a este proyecto. Tampoco eran adecuados los intérpretes aborígenes que había disponibles. Se hizo un breve intento para asegurar la ayuda de una persona nativa que ayudaba en la enseñanza, pero el experimentador opinó que no tenía un control real sobre la comunicación. (El propio intérprete demostró más tarde ser no conservador y podría haber influenciado a los niños contra una respuesta de conservación). De 
Lemos (1966, pp. 372-3) ha realizado las mismas observaciones. Como también ha señalado De Lemos (1969 b, p. 257), no pueden utilizarse preguntas que tengan más de una alternativa, ya que el niño contesta frecuentemente «sí» o «no» simplemente, probablemente a la última alternativa mencionada en la pregunta. Cada alternativa se planteaba por tanto como una pregunta.distinta, o se formulaba la pregunta como " $¿ \mathrm{Y}$ ahora qué pasa?» (Âlmy et al., 1966, p. 51).

\section{Tareas}

Ofrecemos a continuación un resumen de las tareas utilizadas. Los procedimientos detallados se presentan extensamente en otra parte (Dasen, 1970).

1. Conservación de la cantidad. Después de haber realizado correctamente cinco items de control consecutivos, que implicaban cantidades iguales y desiguales, se pedía al sujeto que vertiera la misma cantidad de cordial en dos vasos típicos (A y A'). Luego se pedía al sujeto que vertiera $A^{\prime}$ en $B$, un cilindro de medición alto y delgado. Después de reestablecer la igualdad entre $A$ y $A^{\prime}$, se invitaba al sujeto a verter $A^{\prime}$ en $C$, una placa de cultivo ancha. En cada caso se preguntaba al niño si las cantidades de cordial seguian siendo las mismas o si había más para beber en uno de los vasos. Se preguntaba al niño cuál prefería beber y se le permitía hacerlo.

2. Conservación del peso. Se evaluó la comprensión de la balanza que tenía el sujeto. Después de realizar correctamente cinco items de control consecutivos que implicaban pesos iguales y desiguales, se pedía que el sujeto eligiera dos bolas de plastilina ( $\mathrm{A}$ y $\mathrm{A}^{\prime}$ ) que tuviéran el mismo peso. Luego se pedía que enrollara $A^{\prime}$ en $B$, una "salchicha" larga $y$ delgada. Después de reestablecer la igualdad entre $A$ y $A^{\prime}$ por medio de un control con la balanza, se pedía al sujeto que aplastara $A^{\prime}$ en $C$ (una «torta» plana). Se preguntaba al niño en cada caso si el peso seguía siendo el mismo o si uno era más pesado. También se planteaban las preguntas en términos de si la balanza permanecía «equilibrada" o "bajaba» de un lado.

3. Conservación del volumen. Se colocaban enfrente del niño dos vasos llenos de agua en sus dos tercios, y se señalaban los niveles con gomas. Se pedía al sujeto que predijera la subida del nivel del agua cuando introduciamos en los vasos bolas de plastilina de tamaños iguales y desiguales. Después de haber realizado correctamente cinco items de control consecutivos, se pedía que el sujeto realizara las mismas transformaciones que en la prueba de conservación del peso, y se hacían las preguntas acostumbradas.

4. Conservación de la longitud. La tarea comenzaba con una serie de items de un test de vocabulario. Parte 1: Se colocaban enfrente del niño dos bastones de igual longitud, paralelos y con sus extremos coincidiendo. Se desplazaba un bastón de izquierda a derecha de tal manera que sobrepasara al otro en $5 \mathrm{~cm}$. aproximadamente. Parte 2: Se daba al sujeto uno de los bastones de $16 \mathrm{~cm}$. (A) y cuatro bastones pequeños de $4 \mathrm{~cm}$. (a's) y se pedía que alineara estos últimos con el primero. Nos cerciorábamos de que comprendía que los cuatro cortos equivalían a la longitud de A. Luego se disponían los cuatro a's formando una "W». Parte 3: Se colocaban enfrente del niño dos limpiapipas de longitud desigual, uno recto y uno curvo en forma de zigzag, de tal manera que sus extremos coincidieran. Se preguntaba al niño en cada caso si los dos bastones tenían la misma longitud, si en los dos bastones había que andar la misma distancia de un extremo al otro. No se utilizó la pregunta sobre si nos llevaría el mismo tiempo recorrerlos (De Lemos, 1966), puesto que habría introducido un concepto diferente.

En todos los items de todas las tareas de conservación, se pedía al niño una explicación de su juicio.

5. Seriación. Parte 1: Se daba al sujeto un conjunto de diez bastones sueltos, que aumentaban desde 10,6 a $16 \mathrm{~cm}$ en pasos de $0,6 \mathrm{~cm}$, dispuestos al azar sobre la mesa, y se le mostraba un modelo de seriación que debía copiar. Una vez que el sujeto había comenzado a trabajar se retiraba el modelo, pero se presentaba de nuevo todas las veces que fuera necesario. Parte 2: Se daba el modelo al sujeto y se pedía que colocara los diez bastones sueltos «en el lugar correcto". (Las longitudes de los bastones fueron ideadas de tal manera que fuera posible ina inserción exacta.)

6. Ordenes. Parte 1: Orden lineal. Se pedía al sujeto que copiara una disposición lineal de nueve vestidos en miniatura (recortados en cartulina de colores a fin de que formaran una " $V$ " invertida que permitiera colgarlos de una cuerda). Parte 2: Orden inverso. Se pedía al niño que eligiera exactamente los mismos vestidos que había en el modelo (como en la primera Parte), pero invirtiendo su orden. Esta instrucción algo difícil era formulada de diferentes maneras hasta que el experimentador 
estaba seguro de que el niño había comprendido el problema. Parte 3: Orden circular. El experimentador colocaba cinco items sobre la mesa formando un círculo y pedía al sujeto que copiara la disposición en el mismo orden pero en linea recta.

7. Rotación. Sobre una mesa se colocaban con la misma orientación uno al lado del otro dos modelos idénticos de paisaje, adaptados al paisaje australiano, pero que incluían las mismas características espaciales que los descritos por Piaget e Inhelder (1956, p. 421). Se pedía que el niño nombrara los elementos de uno de los modelos y mostrara en el otro los elementos correspondientes; se advertía el hecho de que los dos modelos eran idénticos. Luego el experimentador colocaba en uno de los modelos una oveja de juguete en varios lugares, pidiendo al niño que colocara su oveja de juguete en la misma posición exactamente (controlando la localización y la dirección "en que miraba"). Una vez que el niño comprendía el problema, se giraba uno de los modelos $180^{\circ}$ y se repetían los mismos items de control. Finalmente, se colocaba una pantalla entre los dos modelos para evitar la posibilidad de una solución puramente perceptiva. Para los items de la prueba, la oveja era colocada sucesivamente en siete posiciones típicas en uno de los modelos y se pedía al niño que encontrara en el modelo rotado la misma posición y dirección. No se pedía al niño que verbalizara su razonamiento.

8. Horizontalidad. Sobre un soporte se colocaba en posición vertical una botella redonda, llena hasta la mitad de agua con color azul. Se presentaba al sujeto un dibujo que correspondía en términos generales, y se pedía que dibujara el agua en la botella. Luego se escondía la botella en una bolsa, de tal manera que se viera la forma pero no el agua, y se realizaba un segundo ítem de control en posición vertical. Parte 1: Anticipación. Se colocaba la botella, todavía escondida en la bolsa, en cinco posiciones diferentes sucesivamente (desde el punto de vista del sujeto: 1. inclinada hacia la derecha; 2. hacia su lado, con el corcho hacia la derecha; 3 . al revés; 4 . inclinada de tal forma que el corcho tocaba a la derecha el soporte; 5 . inclinada a la izquierda). Cada vez que se daba al niño el dibujo correspondiente, se doblaba la hoja de registro para que en cada momento sólo se viera una pintura. Se preguntaba al sujeto dónde estaba el agua y se pedía que lo dibujara. Parte 2: Copia. Se quitaba la bolsa y se repetía el mismo procedimiento en las posiciones en que el sujeto había fallado en la Parte 1. Parte 3: Anticipación después de la copia. Se repetía una vez más el mismo procedimiento con la botella oculta otra vez en la bolsa; esto se hacía sin embargo sólo para las posiciones en las que el sujeto, en la Parte 2, había mejorado su ejecución de la Parte 1. Debe destacarse que ésta fue la única tarea en la que se utilizó material pictórico; sin embargo, era tan sencillo que no debería causar ninguna dificultad.

\section{Secuencia de las tareas}

El orden en que se administraron las tareas fue al azar. Con todo, se contrabalanceó el orden de las tareas de conservación de cantidad, peso y volumen, de forma que tanto en la muestra total como en cada grupo de edad, el número de sujetos que realizaban cada tarea en primer, segundo o tercer lugar fue aproximadamente igual.

No se administraron todas las tareas a todos los grupos de edad. En Areyonga no se administraron las tareas de conservación a los de 6 y 7 años; en la muestra europea, no se administró la conservación del volumen a los de 5 años y la prueba se abandonaba si en el grupo de edad previo el 100 por 100 había logrado la conducta del estadio III. Las tareas de órdenes se presentaron a los siguientes grupos de edad: de 5 a 8 en Canberra, de 6 a 10 en Hermannsburg, y de 6 a 11 en Areyonga.

A los adultos de las muestras aborígenes se les presentaron las siguientes tareas: conservación de la cantidad, peso $\mathrm{y}$ volumen, $\mathrm{y}$ horizontalidad. El número de sujetos en la muestra de Areyonga varía algo en las tareas porque algunos sujetos se marchaban a "dar un paseo» antes de que se terminara la prueba.

\section{Clasificación de las tareas para el análisis de datos}

Las tareas fueron agrupadas del modo siguiente:

Tareas de conservación y lógico-matemáticas: conservación de la cantidad, peso, volumen y longitud; seriación.

Tareas espaciales: órdenes, rotación y horizontalidad.

Se pensó que las tareas de conservación y lógico-matemáticas estaban teóricamente relacionadas con el concepto de número (Piaget, 1941) mientras que las tareas espaciales se seleccionaron así 
para que incluyeran relaciones espaciales topológicas, proyectivas y euclidianas (Piaget e Inhelder, 1956). Las tareas de conservación de longitud, aunque hagan referencia a un contenido espacial, se agruparon con las pruebas lógico-matemáticas por su similaridad estructural con las demás tareas de conservación, y porque las pruebas antropológicas mostraban que los aborígenes tradicionalmente no comparan ni miden longitudes.

Los dos grupos de tareas también pueden ser denominadas, respectivamente: irrelevantes ecológica y culturalmente, y relevantes ecológica y culturalmente.

\section{Puntuación y clasificaciọn}

Las respuestas de los niños fueron registradas en hojas de respuesta especialmente ideadas, y las entrevistas de las tareas de conservación se grabaron en cinta magnetofónica. Luego se clasificaron las respuestas dentro de los estadios de desarrollo de Piaget. Estos estadios y los procedimientos operacionales utilizados para la puntuación y clasificación de las respuestas en estadios han sido descritos en extenso en otra parte (Dasen, 1970). Para las tareas de conservación se aplicaron las mismas convenciones descritas por De Lemos (1969 b, p. 260), excepto en los casos en que los niños parecían contestar al azar o fracasaban en los items de control que fueron clasificados separadamente dentro de una categoría F (para "fracaso en comunicar").
Se atribuyó también un número de puntos a cada respuesta; si la tarea comprendía varios subtests, se sumaban para dar una puntuación por cada tarea. Las puntuaciones de las tareas de conservación y lógico-matemáticas se sumaban para dar la upuntuación lógicomatemática» y las puntuaciones de las tareas espaciales se sumaban para dar la «puntuación espacial». Este sistema de puntuación es, por supuesto, bastante arbitrario pero ofrece la posibilidad de sumar la ejecución de diferentes tareas. Los detalles de la puntuación en puntos y los resultados de cada tarea y grupo de tareas se presentan extensamente en otra parte (Dasen, 1970).

\section{RESULTADOS}

\section{Análisis cualitativo}

Un análisis cualitativo detallado de los resultados puso de manifiesto una correspondencia exacta entre las respuestas y explicaciones dadas por los niños aborígenes y por los niños europeos en Canberra. El niño aborigen puede usar sólo una palabra o dos, o un gesto, en vez de una larga explicación verbal, pero el razonamiento que expresa es exactamente el mismo.

Esta conclusión general necesita una matización: los niños europeos, alrededor de los 10 años y en adelante, comienzan a hacer afirmaciones más complejas que parecen reflejar una nueva ma-

TABLA 1. Conservación de la cantidad (líquidos): porcentaje de sujetos clasificados en cada estadio

\begin{tabular}{|c|c|c|c|c|c|c|c|c|c|c|c|c|c|}
\hline Edad & 5 & 6 & 7 & 8 & 9 & 10 & 11 & 12 & 13 & 1 & 15 & 16 & $\overrightarrow{A d}$. \\
\hline \multicolumn{14}{|c|}{ Canberra $a^{\mathrm{a}}$} \\
\hline C & 0 & 30 & 70 & 90 & 100 & 100 & - & - & & & & & \\
\hline $\mathrm{T}$ & 10 & 10 & 20 & 0 & $\mathbf{0}$ & $\mathbf{0}$ & & & & & & & \\
\hline $\mathrm{NC}$ & 90 & 60 & 10 & 10 & 0 & $\mathbf{0}$ & & & & & & & \\
\hline \multicolumn{14}{|c|}{ Hermannsburg } \\
\hline C & & 0 & 10 & 20 & 40 & 30 & 10 & 50 & & 70 & & 70 & 40 \\
\hline $\mathrm{T}$ & & 10 & 10 & 40 & 10 & 0 & 30 & 10 & & 10 & & 20 & 20 \\
\hline $\mathrm{NC}$ & & 60 & 80 & 30 & 50 & 70 & 60 & 40 & & 20 & & 10 & 40 \\
\hline $\mathrm{F}$ & & 30 & 10 & 0 & $\mathbf{0}$ & 0 & 0 & 0 & & 0 & & 0 & 0 \\
\hline \multicolumn{14}{|c|}{ Areyongab } \\
\hline $\mathrm{C}$ & & & & & 7 & & 0 & & & & 30 & & 30 \\
\hline $\mathrm{T}$ & & & & & 0 & & 0 & & & & 10 & & 20 \\
\hline NC & & & & & 5 & & 9 & & & & 60 & & 50 \\
\hline $\mathrm{F}$ & & & & & 8 & & 1 & & & & 0 & & 0 \\
\hline
\end{tabular}

$\mathrm{C}=$ Conservación.

$\mathrm{T}=$ Transicional

NC $=$ No conservación.

${ }^{2} N=10 S_{s}$ por cada edad.

F = Comunicación fallida.

${ }^{b} N=12,9,15,10,10 S_{s}$ respectivamente. 
nera de pensar sobre los problemas; los niños comienzan a utilizar conceptos formales, algunas veces sin comprenderlos enteramente. Tienden también a formular sus explicaciones como leyes generales (por ejemplo: "siempre hay el mismo peso, hagas lo que hagas, a menos que añadas o quites algo»).

Los sujetos aborígenes no dan estas generalizaciones o explicaciones complejas. Esto puede deberse en parte a la falta de fluidez verbal en inglés. Sin embargo, incluso los sujetos mayores y los adultos que han adquirido un buen dominio de la lengua inglesa no hacen ninguna de estas afirmaciones complicadas. Las propiedades formales del pensamiento, según lo demuestran algunas formulaciones de los niños europeos, están ausentes de las explicaciones que dan los aborígenes.

Se vio que las respuestas y explicaciones dadas por los niños aborígenes podían ser clasificadas sin dificultad dentro de los estadios descritos por Piaget.

\section{Análisis cuantitativo}

En las Tablas 1 a 8 se presentan para cada test el porcentaje de niños clasificados en los diferentes estadios de desarrollo en cada nivel de edad. En cada caso, el Estado III (o C para la conservación) representa el logro del estadio operacional concreto.

TABla 2. Conservación de peso: porcentaje de sujetos clasificados en cada estadio

\begin{tabular}{|c|c|c|c|c|c|c|c|c|c|c|c|c|c|}
\hline Edad & 5 & 6 & 7 & 8 & 9 & 10 & 11 & 12 & 13 & 14 & 15 & 16 & Ad. \\
\hline \multicolumn{14}{|c|}{ Canberra $a^{\mathrm{a}}$} \\
\hline $\mathrm{C}$ & 0 & 0 & 20 & 60 & 80 & 20 & 50 & 80 & & & & & \\
\hline $\mathrm{T}$ & 0 & 30 & 40 & 30 & 0 & 20 & 20 & 20 & & & & & \\
\hline $\mathrm{NC}$ & 100 & 70 & 40 & 10 & 20 & 60 & 30 & 0 & & & & & \\
\hline \multicolumn{14}{|c|}{ Hermannsburg } \\
\hline $\mathrm{C}$ & & 0 & 0 & 10 & 10 & 10 & 10 & 20 & & 0 & & 50 & 20 \\
\hline $\mathrm{T}$ & & 10 & 20 & 0 & 20 & 0 & 20 & 10 & & 0 & & 40 & 0 \\
\hline $\mathrm{NC}$ & & 70 & 50 & 60 & 70 & 90 & 70 & 70 & & 0 & & 10 & 80 \\
\hline $\mathbf{F}$ & & 10 & 40 & 20 & 0 & $\mathbf{0}$ & 0 & 0 & & 0 & & 0 & ก \\
\hline \multicolumn{14}{|c|}{ Areyonga } \\
\hline C & & & & & & & & & & & 9 & & 10 \\
\hline$T$ & & & & & & & & & & & 37 & & 10 \\
\hline NC. & & & & & & & & & & & 27 & & $\begin{array}{r}80 \\
0\end{array}$ \\
\hline $\mathrm{F}$ & & & & & & & & & & & 27 & & 0 \\
\hline
\end{tabular}

${ }^{a} N=10 S s$ por edad.

${ }^{\mathrm{b}} N=12,9,15,10,10 S_{s}$ respectivamente.

Tabla 3. Conservación de volumen: porcentaje de sujetos clasificados en cada edad

\begin{tabular}{|c|c|c|c|c|c|c|c|c|c|c|c|c|c|}
\hline Edad & 5 & 6 & 7 & 8 & 9 & 10 & 11 & 12 & 13 & 14 & 15 & 16 & $A d$. \\
\hline \multicolumn{14}{|c|}{ Canberra } \\
\hline $\mathrm{C}$ & & 10 & 10 & 10 & 50 & 10 & 60 & 50 & & & & & \\
\hline $\mathrm{T}$ & & 20 & 40 & 50 & 30 & 10 & 10 & 40 & & & & & \\
\hline NC & & 70 & 50 & 40 & 20 & 80 & 30 & 10 & & & & & \\
\hline \multicolumn{14}{|c|}{ Hermannsburga } \\
\hline $\mathrm{C}$ & & 10 & 10 & 0 & 30 & 30 & 10 & 20 & & 20 & & 60 & 30 \\
\hline $\mathrm{T}$ & & 10 & 20 & 40 & 30 & 60 & 20 & 30 & & 30 & & 30 & 0 \\
\hline NC & & 40 & 40 & 20 & 40 & 10 & 70 & 50 & & 50 & & 10 & 70 \\
\hline $\mathrm{F}$ & & 40 & 30 & 30 & 0 & 0 & 0 & 0 & & 0 & & 0 & 0 \\
\hline \multicolumn{14}{|c|}{ Areyongab } \\
\hline C & & & & & & & & & & & & & \\
\hline $\mathrm{T}$ & & & & & & & & & & & 0 & & 0 \\
\hline $\mathrm{NC}$ & & & & & 7 & & & & & & 0 & & 100 \\
\hline $\mathrm{F}$ & & & & & & & 0 & & & & 0 & & 0 \\
\hline
\end{tabular}

$N=10 S_{s}$ por edad.

${ }^{\circ} N=12,9,15,11,10 S_{s}$ respectivamente. 


\section{Estudios}

TABla 4. Conservación de longitud: porcentaje de sujetos clasificados en cada estadio

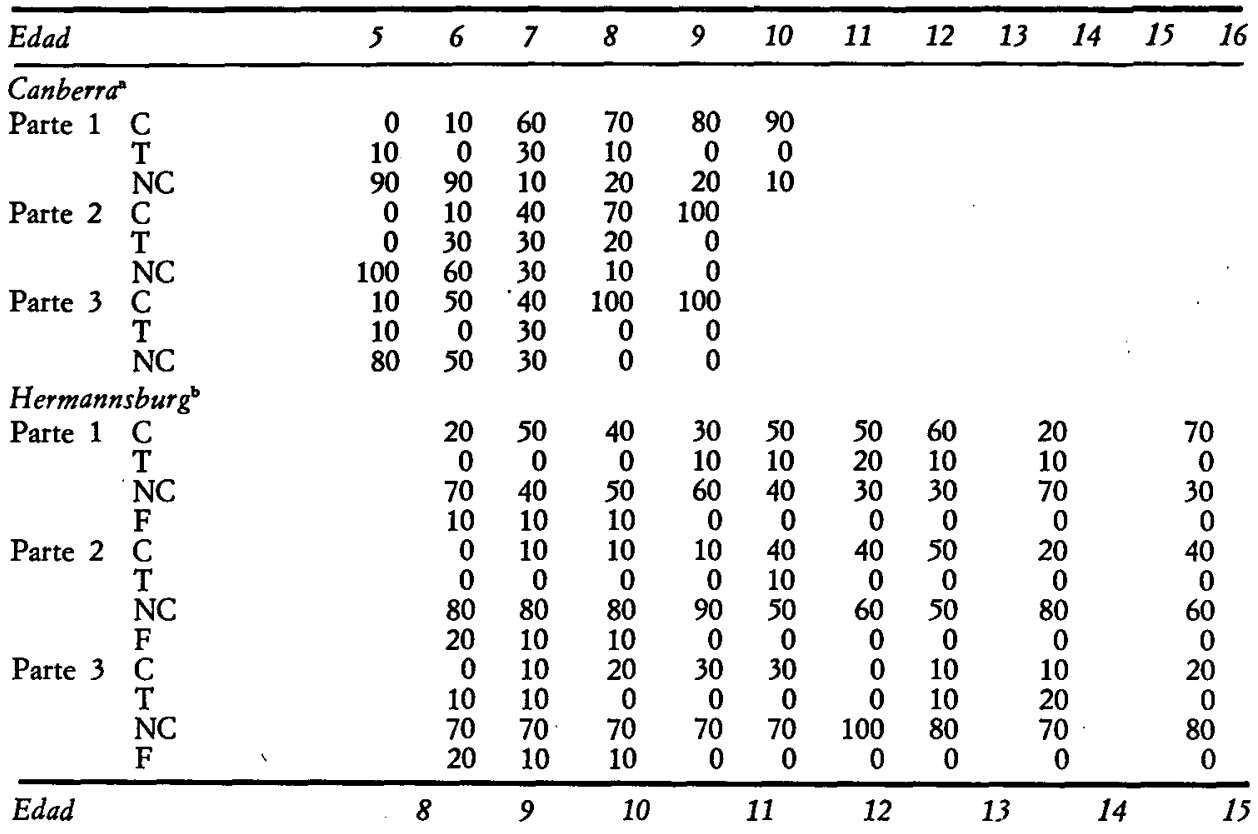

Areyonga ${ }^{\mathrm{b}}$

Parte 1

$\mathrm{T}$

Parte $2 \stackrel{\mathrm{F}}{\mathrm{C}}$

Parte 3 F

$\mathrm{F}$

$\mathrm{NC}$

$\mathrm{F}$

$\begin{array}{rc}17 & 25,0 \\ 25 & 12,5 \\ 58 & 62,5 \\ 0 & 0 \\ 8 & 0 \\ 17 & 0 \\ 75 & 87,5 \\ 0 & 12,5 \\ 17 & 12,5 \\ 0 & 12,5 \\ 83 & 75,0 \\ 0 & 0\end{array}$

37,5

12,5

37,5

12,5

25,0

12,5

50,0

12,5

50,0

0

37,5

12,5

- $N=10 S_{s}$ por edad.

${ }^{\circ} N=12,8,15,8 S s$ respectivamente.

Tabla 5. Seriación: porcentaje de sujetos clasificados en cada estadio

\begin{tabular}{|c|c|c|c|c|c|c|c|c|c|c|c|c|}
\hline Edad & 5 & 6 & 7 & 8 & 9 & 10 & 11 & 12 & 13 & 14 & 15 & 16 \\
\hline \multicolumn{13}{|l|}{ Canberra ${ }^{\mathbf{a}}$} \\
\hline Estadio III & 0 & 30 & 60 & 100 & & & & & & & & \\
\hline II & 40 & 60 & 40 & 0 & & & & & & & & \\
\hline$»$ & 60 & 10 & 0 & 0 & & & & & & & & \\
\hline \multicolumn{13}{|c|}{ Hermannsburg" } \\
\hline \multicolumn{2}{|l|}{ Estadio III } & 0 & $\mathbf{0}$ & 10 & 10 & 40 & 60 & 80 & & 30 & \multirow{2}{*}{\multicolumn{2}{|c|}{$\begin{array}{r}100 \\
0\end{array}$}} \\
\hline$" \quad$ II & & 30 & 70 & 70 & 90 & 60 & 40 & 20 & & 0 & & \\
\hline " I & & 70 & 30 & 20 & 0 & 0 & 0 & 0 & & 0 & & 0 \\
\hline \multicolumn{13}{|l|}{ Areyonga } \\
\hline \multirow{2}{*}{\multicolumn{2}{|c|}{$\begin{array}{l}\text { Estadio III } \\
\Downarrow\end{array}$}} & \multicolumn{2}{|c|}{0} & \multicolumn{2}{|c|}{17} & \multicolumn{2}{|c|}{33,3} & \multirow{2}{*}{\multicolumn{2}{|c|}{27}} & & \multirow{2}{*}{\multicolumn{2}{|c|}{75}} \\
\hline & & \multirow{2}{*}{\multicolumn{2}{|c|}{$\begin{array}{l}62,5 \\
375\end{array}$}} & \multirow{2}{*}{\multicolumn{2}{|c|}{$\begin{array}{l}66 \\
17\end{array}$}} & \multirow{2}{*}{\multicolumn{2}{|c|}{11,1}} & \multirow{2}{*}{\multicolumn{3}{|c|}{$\begin{array}{l}60 \\
13\end{array}$}} & \multirow{2}{*}{\multicolumn{2}{|c|}{25}} \\
\hline$»$ & & & & & & & & & & & & \\
\hline
\end{tabular}

${ }^{\mathrm{a}} N=10 S_{s}$ por edad.

${ }^{b} N=8,12,9,15,8$ Ss respectivamente. 
TABLA 6. Ordenaciones: porcentaje de sujetos clasificados en cada.estadio

\begin{tabular}{|c|c|c|c|c|c|c|c|}
\hline Edad & 5 & 6 & 7 & 8 & 9 & 10 & 11 \\
\hline \multicolumn{8}{|l|}{ Canberra" } \\
\hline $\begin{array}{cl}\text { Estadio } & \text { III } \\
» & \text { Int. } \\
» & \text { IIb } \\
» & \text { IIa }\end{array}$ & $\begin{array}{r}20 \\
0 \\
50 \\
30\end{array}$ & $\begin{array}{r}80 \\
0 \\
20 \\
0\end{array}$ & $\begin{array}{r}80 \\
20 \\
0 \\
0\end{array}$ & $\begin{array}{r}100 \\
0 \\
0 \\
0\end{array}$ & $\begin{array}{r}100 \\
0 \\
0 \\
0\end{array}$ & - & \\
\hline \multicolumn{8}{|c|}{ Hermannsburg } \\
\hline $\begin{array}{cl}\text { Estadio } & \text { III } \\
» & \text { Int. } \\
» & \text { IIb } \\
» & \text { IIa }\end{array}$ & - & $\begin{array}{l}50 \\
10 \\
30 \\
10\end{array}$ & $\begin{array}{r}70 \\
20 \\
10 \\
0\end{array}$ & $\begin{array}{r}80 \\
20 \\
0 \\
0\end{array}$ & $\begin{array}{r}100 \\
0 \\
0 \\
0\end{array}$ & $\begin{array}{r}100 \\
0 \\
0 \\
0\end{array}$ & - \\
\hline \multicolumn{8}{|l|}{ Areyonga ${ }^{\mathrm{a}}$} \\
\hline $\begin{array}{cl}\text { Estadio } & \text { III } \\
» & \text { Int. } \\
» & \text { IIb } \\
» & \text { IIa }\end{array}$ & & $\begin{array}{c}0 \\
33,3 \\
66,6 \\
0\end{array}$ & $\begin{array}{r}40 \\
40 \\
10 \\
0\end{array}$ & $\begin{array}{r}100 \\
0 \\
0 \\
0\end{array}$ & $\begin{array}{r}88 \\
0 \\
12 \\
0\end{array}$ & $\begin{array}{r}100 \\
0 \\
0 \\
0\end{array}$ & $\begin{array}{r}100 \\
0 \\
0 \\
0\end{array}$ \\
\hline
\end{tabular}

a $N=10$ Ss por edad.

${ }^{b} N=3,5,4,8,6,2 S_{s}$ respectivamente.

TABLA 7. Rotación: porcentaje de sujetos clasificados en cada estadio

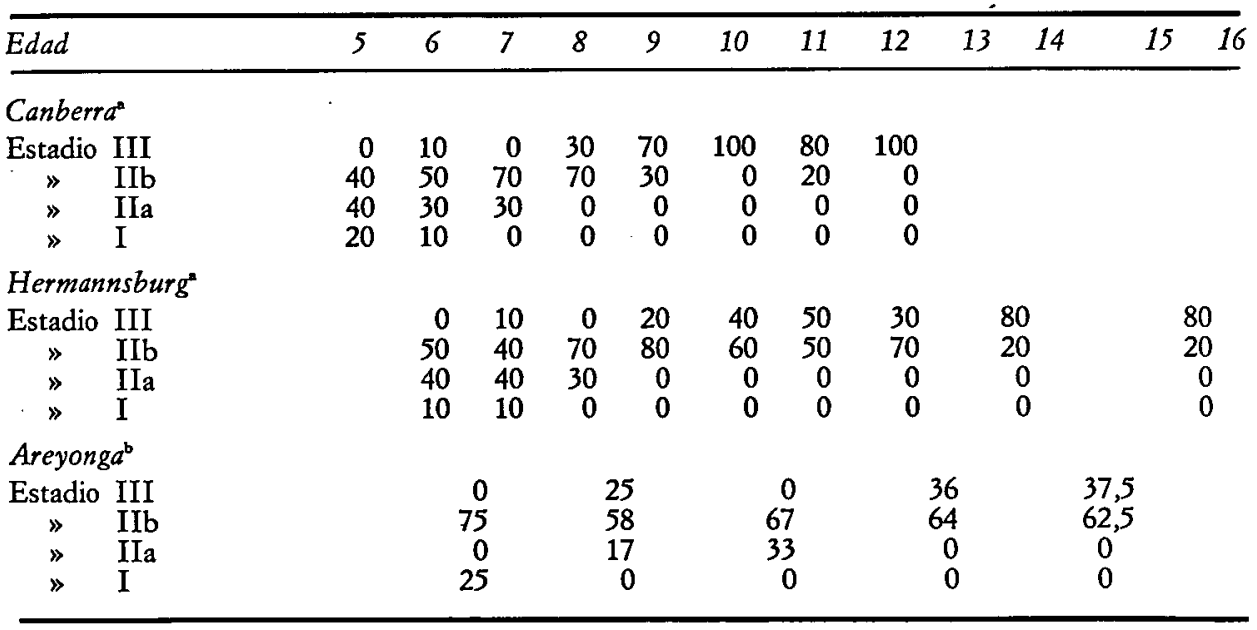

- $N=10 S_{s}$ por edad.

${ }^{\circ} N=8,12,9,14,8$ Ss respectivamente.

Se juntaron las puntuaciones lógicomatemáticas de las tres muestras y se transformaron en puntuaciones $z^{\prime}$ con una media de 50 y una desviación típica de 10 . Se realizó el mismo cálculo para las puntuaciones espaciales. En la Tabla 9 se presentan para cada muestra y cada nivel de edad las medias y desviaciones típicas de las puntuaciones ' $\mathrm{z}$ lógico-matemáticas y espaciales.

\section{DISCUSION}

\section{Hipótesis 1}

Siempre que se pueda dar la comparación, los resultados obtenidos en Canberra son similares a los presentados en Ginebra (Piaget e Inhelder, 1969; Inhelder, 1968); esto es válido también para las comparaciones con datos no publi- 
cados (Vinh-Bang, en preparación). La sorprendente disminución en la conservación del peso ( $\mathrm{y}$ en un menor grado del volumen) que es evidente en la muestra de Canberra a los 10 y 11 años se atribuyó, después de un análisis cuidadoso de los protocolos y de volver a pasar la prueba a la misma muestra y a otras, a la interferencia de conceptos quasi-formales como la gravedad y la presión (Dasen y Christie, 1972). Resultados similares fueron presentados por Goodnow (1962, p. 9) y Pinard et al. (1969, p. 12).

El ritmo de desarrollo de todos los conceptos estudiados es mucho más lento en ambas muestras de aborígenes. Si consideramos la consecución del estadio operacional concreto, el nivel del 100 por 100 sólo se alcanza en los tests de seriación $\mathrm{y}$ órdenes. En la mayoría de los casos, las curvas de desarrollo son asintóticas en las edades superiores. Esto significa que una mayor o menor gran proporción de aborígenes (dependiendo de la muestra y el concepto con- creto) no desarrolla completamente estos conceptos operacionales concretos. De hecho, se encontró que la frecuencia del pensamiento operacional es menor en los adultos que en los niños mayores escolarizados. Puesto que, teóricamente, un concepto que se ha adquirido, no es probable que se pierda, podemos suponer que estos adultos no han alcanzado el estadio operacional concreto a los 14 y 16. años. Podemos interpretar la actuación superior de los niños mayores escolarizados o bien como si se debiera a la mejora educativa o bien a la posibilidad de que un mayor contacto europeo tuviera más influencia en los niños que en los adultos. Quizás la educación y/o el contacto europeo sean efectivos solamente durante un "periodo crítico" en la niñez, y podemos suponer que el contacto europeo es mayor para los niños de hoy que lo fue para sus padres. Un estudio longitudinal que se está llevando a cabo actualmente en Hermannsburg podría proporcionar nueva información.

Una característica de los resultados en

TABLA 8. Horizontalidad: porcentaje de sujetos clasificados en cada estadio

\begin{tabular}{llllllllllllll}
\hline Edad & 5 & 6 & 7 & 8 & 9 & 10 & 11 & 12 & 13 & 14 & 15 & 16 & $A d$. \\
\hline
\end{tabular}

\section{Canberra}

Parte 1

$\begin{array}{llrrrrrrrr}\text { Estadio IIIb } & 0 & 0 & 0 & 30 & 10 & 20 & 70 & 50 \\ \Rightarrow & \text { Int. } & 10 & 20 & 30 & 40 & 70 & 70 & 30 & 50 \\ \Rightarrow \quad \text { IIb } & 30 & 10 & 50 & 30 & 20 & 10 & 0 & 0 \\ \Rightarrow \quad \text { IIa } & 60 & 50 & 20 & 0 & 0 & 0 & 0 & 0 \\ \Rightarrow \quad \text { I } & 0 & 20 & 0 & 0 & 0 & 0 & 0 & 0 \\ \text { artes 1-3 } & & & & & . & & & \\ \text { IIIa y IIIb } & 0 & 10 & 20 & 60 & 50 & 70 & 100 & 90\end{array}$

Hermannsburg ${ }^{b}$

Parte 1

Estadio IIIb

$\begin{array}{ll}\gg & \text { Int. } \\ \gg & \text { IIb } \\ \gg & \text { IIa } \\ \gg & \text { I }\end{array}$

Partes 1-3

IIIa y IIIb

Areyonga $a^{\mathbf{b}}$

Estadio IIIb

$\gg$ Int.

$\gg$ IIb

$\gg \quad$ IIa

90

Partes 1-3

IIIa y IIIb

$\begin{array}{rrrrr}0 & 0 & 20 & 0 & 20 \\ 0 & 10 & 10 & 50 & 30 \\ 60 & 20 & 30 & 30 & 50 \\ 30 & 70 & 30 & 20 & \\ 10 & 0 & 10 & 0 & \end{array}$

$\begin{array}{rrr}10 & 0 & 30 \\ 60 & 70 & 40 \\ 20 & 30 & 30 \\ 10 & 0 & \\ 0 & 0 & \\ 50 & 30 & 50\end{array}$

30

$40 \quad 50 \quad 50$

40

$30 \quad 10$

10

10

$0 \quad 0$

0
0

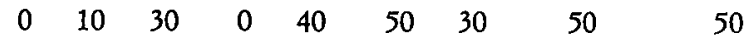

60

\footnotetext{
${ }^{a} N=10 S s$ por edad.

${ }^{\mathrm{b}} \mathrm{N}=8,12,9,15,10,10 \mathrm{Ss}$ respectivamente.
} 
la conservación de la cantidad que requiere algún comentario eś él descenso en el número de respuestas de conservación en las muestras aborígenes de 10 y 11 años (tabla 1). En los datos de $\mathrm{De}$ Lemos existe una discontinuidad similar a los 11 años; la actuación relativamente mejor de los niños más pequeños se interpretó como debida a los nuevos métodos de enseñanza que se habían introducido recientemente (De Lemos, 1969 b. p. 267). Si esta interpretación fuera correcta, podría esperarse que, en los cinco años que separan los dos estudios, esta ventaja sería mantenida por todos los niños mayores de 14 y 15 años. Ya que este descenso se sigue dando en la misma edad, parece que es un caso específico de la edad. Una posible explicación (De Lemos, Bovet, comunicaciones personales) seria que la relativamente buena actuación en edades tempranas no representaba una conducta de conservación verdadera, sino que era una pseudoconservación, como las encontradas por Bovet (1973) en los niños argelinos. Para responder a esta pregunta deberiamos haber utilizado procedimientos adicionales como las tareas de aprendizaje (Bovet, 1973).

Los ritmos de desarrollo de los conceptos de conservación y lógico-matemáticos presentados en este estudio $y$ por De Lemos $(1966,1969$ b) y por De Lacey $(1970 \mathrm{~b})$ son extremadamente lentos en los aborígenes de bajo-contacto. En las tareas de conservación, de las que poseemos muchos datos transculturales, los ritmos sólo se pueden comparar con los presentados por Kelly (1970) y están ligeramente por debajo de los obtenidos por Waddell (1968) y Prince (1969 a) con niños de Nueva Guinea Highland. Muchos de los niños aborígenes no llegan a alcanzar el nivel operacional concreto, y el pensamiento lógico formal (juzgando por la tarea de conservación del volumen, que está considerada como intermedia entre el nivel operacional concreto y el formal) está casi ausente. Aunque estos hechos proceden de un análisis cuantitativo de los resultados, representan una limitación a la generalidad transcultural de los estadios de Piaget.

Aunque la correlación entre el logro de los conceptos de conservación y la actuación escolar ha sido puesta recientemente en duda en una situación transcultural (Heron, 1971), es probable que la baja realización educativa de los niños aborígenes esté ligada al fracaso en el desarrollo de estructuras de pensamiento que son tan básicas en el sistema escolar europeo que, hasta recientemente, se ha supuesto que existían sin nin- gún intento de comprobarlas o enseñarlas.

En resumen, teniendo en cuenta el análisis cuantitativo de los resultados y los ritmos de desarrollo presentados en las Tablas 1 a 9 , se ha confirmado la Hipótesis 1.

\section{Hipótesis 2}

Se calcularon las pruebas chi-cuadrado con el número de sujetos que había alcanzado en cada muestra aborigen el Estadio III en cada prueba (Tabla 10).

Todos los valores de chi-cuadrado, excepto uno, son estadísticamente significativos o están cerca de la significación para las pruebas lógico-matemáticas. Por otra parte, sólo un valor de chi-cuadrado está cerca de la significación para las pruebas espaciales.

Este análisis está confirmado por análisis de varianza de tratamiento por niveles en las puntuaciones z' lógico-matemáticas y espaciales, en las que los tratamientos del valor $F$ (contacto europeo) es estadísticamente significativo $(F=$ $=8,727, d f=1, p<0,01$ ) solamente en las puntuaciones lógico-matemáticas.

Aunque la interacción de los valores $\mathrm{F}$ (contacto europeo por edad) no es estadísticamente significativa, un examen tanto de los valores z' (Tabla 9) como de los resultados de las pruebas individuales (Tablas 1 a 8 ) pone de manifiesto que la diferencia entre las dos muestras aborígenes aumenta con la edad en las puntuaciones lógico-matemáticas así como en las espaciales, descubrimiento que corrobora los resultados obtenidos por De Lacey con tareas de clasificación (De Lacey, 1970 a).

De este modo, se mantiene la Hipótesis 2. Hay que señalar que la influencia del contacto europeo es más marcada cuando nos referimos a conceptos que son menos relevantes para la cultura aborigen.

\section{Hipótesis 3}

En la muestra europea, las puntuaciones medias de las pruebas espaciales son consistentemente más bajas que las puntuaciones medias de las pruebas ló gico-matemáticas (Tabla 9) mientras que en las dos muestras aborígenes sucede lo contrario: las puntuaciones medias de las pruebas espaciales son consistentemente más altas que las puntuaciones medias de las lógico-matemáticas. Los análisis de varianza de tratamiento por niveles (Tabla 11) confir- 
TABLA 9. Test lógico-matemáticos y espaciales: puntuaciones $z^{\prime}$

\begin{tabular}{llllllllllllllllllllll}
\hline Edad & 5 & 6 & 7 & 8 & 9 & 10 & 11 & 12 & 13 & 14 & 15 & 16 & $\begin{array}{l}\text { Total } \\
\text { muestra }\end{array}$ \\
\hline
\end{tabular}

Canberra

Lógico-matemático $\bar{x}$

$\mathrm{SD}$

Espacial $\bar{x}$

$\mathrm{SD}$

\begin{tabular}{|c|c|c|c|c|c|c|c|}
\hline 36,1 & 45,6 & 54,5 & 59,7 & 63,8 & 59,1 & 63,9 & 64,4 \\
\hline 2,8 & 6,2 & 5,5 & 5,0 & 5,0 & 4,0 & 4,4 & 3,2 \\
\hline 32,2 & 42,1 & 45,5 & 54,6 & 57,2 & 59,3 & 61,0 & 60,9 \\
\hline 4,9 & 6,4 & 4,8 & 4,3 & 3,4 & 1,7 & 2,4 & 3,0 \\
\hline
\end{tabular}

Hermannsburg

Lógico-matemático

$\begin{array}{ll}\bar{x} \\ \text { Espacial } & \bar{x} \\ & \text { SD }\end{array}$

$\begin{array}{rrrrrrrr}37,1 & 41,1 & 43,8 & 48,7 & 49,6 & 47,1 & 51,6 & 52,6 \\ 3,8 & 4,6 & 4,9 & 8,2 & 7,2 & 5,0 & 6,6 & 4,2 \\ 36,0 & 42,3 & 44,1 & 49,0 & 51,9 & 53,3 & 54,4 & 58,5 \\ 4,8 & 7,9 & 9,0 & 6,3 & 6,9 & 8,5 & 2,8 & 2,6\end{array}$

Areyonga

Lógico-matemático

$\begin{array}{ll}\bar{x} \\ \text { Espacial } & \bar{x} \\ & \mathrm{SD}\end{array}$

$\begin{array}{rr}36,8 & 45,6 \\ 2,4 & 5,1 \\ 36,6 & 47,9 \\ 9,1 & 8,4\end{array}$

44,9
4,9
48,0
6,8

45,5
6,1
50,9
5,7

50,5
5,2
55,4
6,8


Tabla 10. Comparación del número de sujetos clasificados en el Estadio III en las muestras Hermannsburg y Areyonga

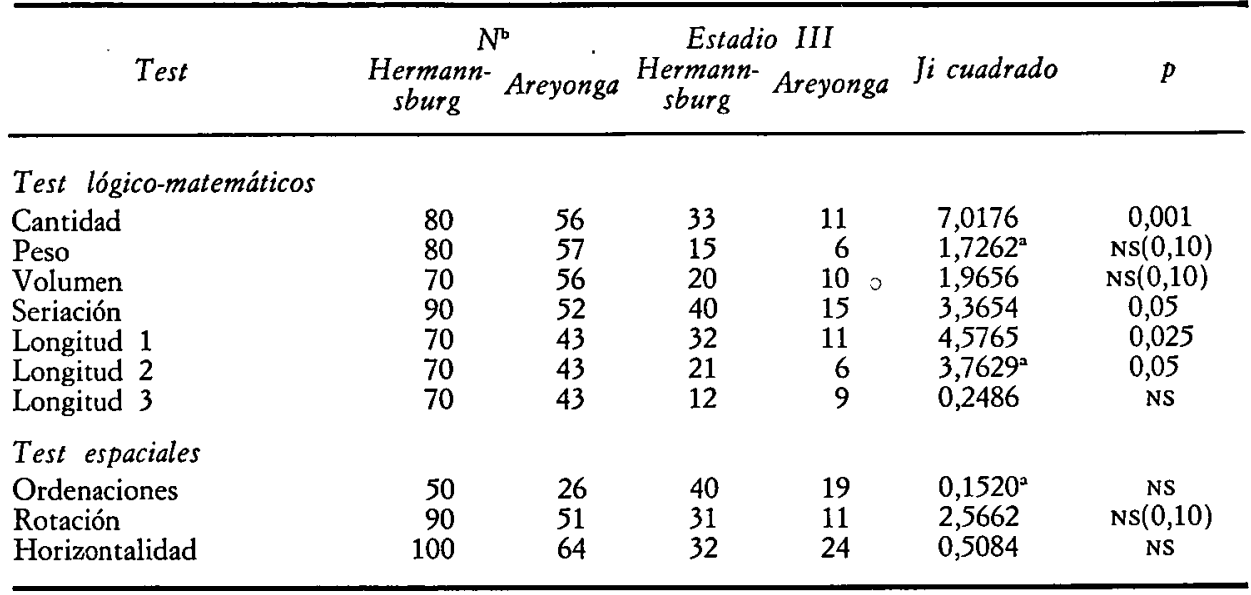

- Aplicada la corrección de Yates para la continuidad de la variable.

- El número de sujetos varía con la categoría de edad en que se aplicaban los tests; entre los Areyonga, algunos sujetos abandonaban la prueba antes de terminar.

man que las diferencias observadas son estadísticamente significativas. Aunque la interacción de los valores $F$ no sea estadísticamente significativa, un examen de los valores $z^{\prime}$ (Tabla 9) indica que las diferencias relativas entre el desarrollo de los conceptos lógico-matemáticos y espaciales aumenta con la edad.

En otras palabras, en nuestras muestras los aborígenes, por término medio, adquieren el conjunto determinado de operaciones espaciales que estamos estudiando antes de adquirir el conjunto determinado de las operaciones lógicomatemáticas, mientras que los europeos de nuestra muestra encuentran relativamente más fáciles las pruebas lógicomatemáticas. De esta forma se mantiene la Hipótesis 3.

Sin embargo, por el hecho de que las habilidades espaciales que necesita un pueblo de economía nómada de caza y recolección son hoy en día (y de hecho, tradicionalmente) más relevantes para el pueblo Pitjantjara de Areyonga que para el más aculturado de Aranda en Hermannsburg, uno podría haber esperado que el desarrollo operacional de la muestra de Areyonga, en relación con las tareas espaciales, fuera superior al de la muestra de Hermannsburg. Este no es el caso, ya que la diferencia entre las dos muestras es estadísticamente significativa en las tareas lógico-matemáticas, pero no en las espaciales (véase discusión anterior).

Berry (1966 b) obtuvo resultados simi- lares: los esquimales con mayor aculturación puntuaron más alto en las pruebas espaciales (actuación) que los esquimales tradicionales. Esto se debe posiblemente a que los conceptos espaciales (en el estudio de Berry, habilidades espaciales) que estamos estudiando son sólo parcialmente equivalentes a los que los aborígenes (los esquimales respectivamente) necesitan para sobrevivir, mientras que para la cultura europea son conceptos espaciales típicamente relevantes. Resultaría interesante analizar, en términos menos generales de lo que hemos hecho aquí, los conceptos y habilidades espaciales que actualmente necesita el pueblo nómada y construir pruebas de acuerdo con ello.

La relación que hemos establecido así entre ecología, cultura y desarrollo operacional es sólo correlacional. Es necesario investigación adicional que varíe la variable ecologia-cultura, utilizando posiblemente un tipo de diseño parecido. al de Berry (1971).

Además, son posibles explicaciones alternativas y que necesitan ser excluidas por experimentación posterior. Una de estas objeciones se refiere al tipo de tareas utilizadas: todas las tareas espaciales implicaban algún tipo de manipulación por parte del sujeto y una expresión de la conducta no verbal en su mayor parte; por otra parte, las tareas así denominadas lógico-matemáticas implicaban un juicio verbal (conservación), excepto en la tarea de seriación, que es 
la única tarea lógico-matemática en que una de las muestras aborigenes alcanza un 100 por 100 de éxitos. Por lo tanto la diferencia entre los dos tipos de tareas podría estar justificada simplemente por la interferencia de un factor verbal. Los resultados de una prueba lógicomatemática no verbal en su mayor parte, el test de reclasificación de Nixon (siguiendo a De Lacey, 1970 a), que fue administrado a la muestra de Hermanns- burg en la primera fase de un estudio longitudinal de seguimiento, confirman que esto es improbable. Este test incluye cinco reclasificaciones sucesivas de objetos de acuerdo con tres dimensiones: altura, anchura y color. En la Tabla 12 presentamos el porcentaje de sujetos que ha alcanzado el Estadio III. La curva de desarrollo es asintótica, igual que las obtenidas en las tareas de conservación.

TABLA 11. Análisis de varianza: puntuacinones $z$ lógico-matemáticas y espaciales

\begin{tabular}{|c|c|c|c|c|c|c|c|c|c|}
\hline \multirow{2}{*}{ Fuente de variación } & \multicolumn{3}{|c|}{ Canberra } & \multicolumn{3}{|c|}{ Hermmansburg } & \multicolumn{3}{|c|}{ Areyonga } \\
\hline & $d f$ & $\mathrm{~F}$ & $p$ & $d t$ & $\mathrm{~F}$ & $p$ & $d f$ & $\mathrm{~F}$ & $p$ \\
\hline Inter & 15 & 50,542 & 0,01 & 17 & 12,464 & 0,01 & 9 & 6,152 & 0,01 \\
\hline $\begin{array}{l}\text { Tratamientos (lógico- } \\
\text { matemático espacial) } \\
\text { Niveles (edad) } \\
\text { Interacción }\end{array}$ & $\begin{array}{l}1 \\
7 \\
7\end{array}$ & $\begin{array}{r}36,701 \\
101,333 \\
1,729\end{array}$ & $\begin{array}{c}0,01 \\
0,01 \\
\text { NS }\end{array}$ & $\begin{array}{l}1 \\
8 \\
8\end{array}$ & $\begin{array}{r}4,877 \\
25,015 \\
0,863\end{array}$ & $\begin{array}{c}0,05 \\
0,01 \\
\text { NS }\end{array}$ & $\begin{array}{l}1 \\
4 \\
4\end{array}$ & $\begin{array}{r}5,582 \\
11,940 \\
0,505\end{array}$ & $\begin{array}{c}0.05 \\
0,01 \\
\text { NS }\end{array}$ \\
\hline
\end{tabular}

TABLA 12. Porcentaje de sujetos que alcanzan el Estadio III en el test de reclasificación de Nixon (estudio longitudinal de los Hermanssburg)

\begin{tabular}{lrrrrrr}
\hline Edad & 6 & 7 & 8 & 10 & 12 & 14 \\
\hline Estadio III (\%) & 9 & 31 & 25 & 64 & 40 & 50 \\
$N$ & 11 & 13 & 12 & 11 & 10 & 10 \\
\hline
\end{tabular}

\section{CONCLUSION}

Piaget (1966) ha sugerido que la investigación transcultural podría ofrecer la posibilidad de distinguir la influencia relativa de cuatro factores en el desarrollo de las funciones cognitivas:

1. Factores biológicos (maduración del sistema nervioso);

2. Factores de equilibración y autorregulación, que corresponden "a las formas secuenciales en la coordinación general de las acciones de los individuos que interactúan con su medio físicon;

3. Factores sociales generales: interacción entre niños o entre adultos y niños;

4. Transmisión educativa y cultural.

Sin embargo, el presente estudio no nos permite juzgar la importancia relativa de cada uno de estos factores. Por un lado, el hecho de que los conceptos se desarrollen siguiendo los mismos subestadios en ambas culturas sugiere que los factores biológicos y de equilibración son en alguna medida universales.
Por otra parte, el ritmo extremadamente lento de desarrollo encontrado en éste y en otros estudios (De Lemos, 1966, $1969 \mathrm{~b}$; De Lacey, $1970 \mathrm{a}, 1970 \mathrm{~b}$ ) señala el hecho de que los factores sociales y culturales son más importantes para el desarrollo cognitivo de lo que Piaget habia hipotetizado. El presente estudio, centrado en la influencia de las variables de contacto europeo y ecológicas y culturales en general, acentúa la importancia del cuarto factor de Piaget. Con todo, el ritmo de desarrollo lento puede deberse parcialmente a la malnutrición (Maxwell y Elliot, 1969; José y Welch, 1970; Tatz, 1970) que posiblemente puede afectar al factor 1.

Tanto la observación personal de las conductas de crianza de los niños como pruebas informales (Hamilton, comunicación personal) sugieren que la interacción del niño aborigen con su ambiente (factor 2) y con los adultos está fuertemente restringida por las costumbres tradicionales. De acuerdo con $\mathrm{Ha}$ milton, a los bebés se les permite explorar el ambiente dentro de los límites 
de un área de aproximadamente el tamaño del círculo de luz que da la hoguera; si gatean más allá, incluso durante el día. se les vuelve inmediatamente hacia atrás. Probablemente esta conducta resultaba adaptativa en el marco tradicional, pero es posible que dificulte el desarrollo sensorio-motor. En cualquier caso, el medio físico del niño aborigen es extremadamente pobre $y$ monótono comparado con el medio de un niño de clase media europeo. Además, como ha demostrado Zempleni (1970) en los Wolof (Senegal), los objetos no parecen desempeñar un papel de mediadores entre el niño y su madre y otros adultos; esta función la realiza el contacto corporal.

Como consecuencia, la exploración verbal parece estar también desaprobada, y los niños aborígenes no pasan, aparentemente, el período de preguntar «por qué», tan bien conocido por los padres europeos. Esto se debe probablemente a la norma cultural de aceptar sin dudar las leyes de la naturaleza, las costumbres sociales y las decisiones de los mayores. Por otra parte, en la cultura aborigen se desaprueba cualquier clase de competición (Sommerlad y Bellingham, 1972).

En otras palabras; los valores implicitos con relevancia o "ambientalidad» cognitiva (Heron y Simonsson, 1969) no son favorables para el desarrollo del pensamiento operacional; el contacto con la civilización europea proporciona algo de esta "ambientalidad", y los factores ecológico-culturales favorecen el desarrollo de ciertas áreas conceptuales más que otras. Para describir estos factores con mayor precisión y para evaluar su influencia relativa en el desarrollo cognitivo son necesarias investigaciones adicionales.

\section{Nota}

(1) Para una discusión de los requisitos utilizados por la escuela de Ginebra para el establecimiento de una tarea operacional, véase Goodnow, 1969 b, pp. 440-52.

\section{Referencias}

Almy, M., Chittenden, E. y Mirler, R. (1966), Young Children's Tbinking: Studies of Some Aspects of Piaget's theory, Nueva York, Teachers College Press.

Berry, J. W. (1966 b), «Temne and Eskimo perceptual skills», Int. J. Psychol., 1, pp. 207-29.

BERRY, J. W. (1971), «Ecological and cultural factors in spatial perceptual development», en BERRY, J. W. y DASEN, P. R. (eds.), Culture and cognition: readings in cross-cultural psychology, Londres, Methuen, pp. 129-140.

BOVET, M. C. (1973), «Cognitive processes among illiterate children and adults», en BERRY, J. W. y DASEN, P. R. (eds.), Culture and cognition: readings in cross-cultural psychology, Londres, Methuen, pp. 311-334.

Dasen,, P. R. (1970), Cognitive development in Aborigines of Central Australia: concrete operations and perceptual activities. Tesis doctoral inédita, Australian National University, Canberra.

DASEN, P. R. (1972a), «Cross-cultural Piagetian research: a summary», en BERRY, J. W. y DASEN, P. R. (eds.), Culture and cognition: readings in cross-cultural psychology, Londres, Methuen, pp. 409-424.

DASEn, P. R. y Christie, R. D. (1972), «A regression phenomenon in the conservation of weight", Archives de Psychologie, 41 (162), pp. 145-52.

Dawson, J. L. M. (1969), «Attitude change and conflict among Australian Aborigines», Austral. J. Psychol., 21 (2), pp. 101-16.

DE LACEY, P. R. (1970 a), Classificatory performance among Aboriginal and white Australian children, Informe presentado ante el Australian Institute of Aboriginal Studies, Canberra. Multicopia.

DE LACEY, P. R. (1970 b), «A cross-cultural study of classificatory ability in Australia», en BERRY, J. W. y DASEN, P. R. (eds.), Culture and Cognition: readings in cross-cultural psychology, Londres, Methuen, pp. 353-366. 
De Lacey, P. R. (1970 c), "An index of contact for Aboriginal communities», Austral. J. Soc. Issues, 5 (3), pp. 219-23.

De LEMOS, M. M. (1966), The development of the concept of conversation in Australian Aboriginal children. Tesis doctoral inédita, Australian National University.

De Lemos, M. M. (1969 b), «The development of conservation in Aboriginal children», Int. J. Psychol., 4 (4), pp. $255-69$.

Elkin, A. P. (1964), The Australian Aborigines: How to understand them (4th ed.), Sydney, Angus \& Robertson.

Goonnow, J. J. (1962), «A test of milieu effects with some of Piaget's tasks», Psychol. Monogr., 76 (36), núm. 555 completo.

Goodnow, J. J. (1969 a), «Cultural variations in cognitive skills», en PriCe-Williams, D. R. (ed.), Cross-cultural Studies, Harmondsworth, Penguin Books, pp. 246-64.

GreEnFIEld, P. M. (1966), "On culture and conservation», en BrunER, J. S., Olver, R. R. y GreEnfreld, P. M. (eds.), Studies in cognitive growth, Nueva York, Wiley, pp. 225-56. Reimpresión en Price-Williams, 1969.

HellbUSCH, S. (1941), Einfluss der Jagd auf die Lebensformen der Australier, Berlín, Ebering.

HeNDrIKz, E. (1966), A cross-cultural investigation of the number concepts and level of number development in five-year-old urban Shona and European children in southern Rhodesia, Tesis de Licenciatura inédita, Universidad de Londres.

Heron, A. (1971), "Concrete operations, ' $g$ ' and achievement in Zambian children», J. CrossCult. Psycbol., 2 (4), pp. $325-36$.

Heron, A. y Simonsson, M. (1969), «Weight conservation in Zambian children: a nonverbal approach", en BERRY, J. W. y DASEN, P. R. (eds.), Culture and cognition: readings in crosscultural psycbology, Londres, Methuen, pp. 335-350.

INHELDER, B. (1956), "Criteria of the stages of mental development», en TANNER, J. M. e INHELDER, B. (eds.), Discussions on child development, Londres, Tavistock, pp. 75-107.

INHELDER, B. (1968), The diagnosis of reasoning in the mentally retarded, Nueva York, John Day. (Le diagnostic du raisonnement chez les débiles mentaux, publicación original en Neuchâtel, 1943; 2." ed., 1963.)

Kaberry, P. M. (1939), Aboriginal woman, sacred and profane, Londres, Routledge \& Kegan Paul.

KelLY, M. R. (1971), «Some aspects of conservation of quantity and length in Papua and New Guinea in relation to language, sex and years at school", Territory of Papua and New Guinea J. Educ., 7 (1), pp. 55-60.

LLoyd, B. B. (1971 b), «Studies of conservation with Yoruba children of differing ages and experience», Child Develop., 42, pp. 415-28.

Lloyd, B. B. (1972) Perception and cognition: A cross-cultural perspective, Harmondsworth, Penguin Books.

MaLinowski, B. (1963), The family among the Australian Aborigines, Nueva York, Schochen Books.

Maxwell, G. M. y Elliot, R. B. (1969), «Nutritional state of Australian Aboriginal children», Amer. J. Clin. Nutr., 22 (6), pp. 716-24.

MoHSENI, N. (1966); La comparaison des réactions aux épreuves d'intelligence en Iran et en Europe, Tesis inédita, Universidad de París.

NuRcombe, B. y CAWTE, J. E. (1967), «Pattern of behaviour disorder amongst the children of an Aboriginal population», Austr. \& N. Z. J. Psycbiat., 1 (3), pp. 119.33.

Peluffo, N. (1967), «Culture and cognitive problems», Int. J. Psychol., 2 (3), pp. 187-98.

Piaget, J. (1966), «Nécessité et signification des recherches comparatives en psychologie génétique», en BerRy, J. W. y DASEN, P. R. (eds.), Culture and cognition: readings in crosscultural psychology, Londres, Methuen, pp. 299-310.

Piaget, J. e InHELDER, B. (1956), The cbild's conception of space (trad. F. J. Langdon y J. L. Lunzer), Londres, Routledge \& Kegan Paul. (La représentation de l'espace chez l'enfant, París, PUF, 1948.)

Piaget, J, e INhelder, B. (1969), «Intellectual operations and their development», en Fraisse, P. y PIAGET, J. (eds.), Experimental psychology: Its scope and method, vol. 7, Intelligence, Londres, Routledge \& Kegan Paul. («Les opérations intellectuelles et leur développement», en Traité de psychologie expérimentale, vol. 7, L'intelligence, París, PUF, 1963.)

Pinard, A. y Laurendeau, M. (1969), "'Stage' in Piaget's cognitive developmental theory: exegesis of a concept», en Elkind, D. y Flavell, J. H. (eds.), Studies in Cognitive Development, Nueva York, Oxford University Press, pp. 121-70.

Poole, H. E. (1968), «The effect of urbanization upon scientific concept attainment among Hausa children of northern Nigerias, Brit. J. Educ. Psychol., 38, pp. 57-63.

Prince, J. R. (1969 a), Science concepts in a Pacific culture, Sydney, Angus \& Robertson.

Sommerlad, E. A. y Bellingham, W. P. (1972), «Cooperationi-competition: a comparison of Australian European and Aboriginal schoolchildren», J. Cross-Cult. Psychol., 3 (2), pp. 149-57. 
Strehlow, T. G. H. (1965), «Culture, social structure and environment in Aboriginal Central Australian», en BERNDT, R. M. y BERNDT, C. H. (eds.), Aboriginal man in Australia, Sydney, Angus \& Robertson, pp. 121-45.

TATZ, C. M. (1970), «The health status of the Australian Aborigines: the need for an interdisciplinary approach», Med. J. Austral., 57th year, 2 (4), pp. 191-6.

VERNON, P. E. (1969), Intelligence and Cultural Environment, Londres, Methuen.

VinH-BAng (en preparación), Standardisation des épreuves opératoires, School of Psychology, Universidad de Ginebra.

WADDELL, V. (1968), Some cultural considerations on the development of the concept of conservation. Ponencia inédita presentada en un seminario de epistemología genética. Australian National University.

ZempLENI, J. (1970), «L'enfant Wolof de 2 à 5 ans (Senegal). Echanges corporels et échanges médiatisés par les objets", Revue de Neuropsychiatrie infantile, 18 (10-11), pp. 785-98. 